\title{
The Design and Magnetic Analysis of MultiDisc and Layer Winding Toroidal Axial Flux Permanent Magnet Open Slotted (MLTAFPMOS) Synchronous Alternator
}

\author{
E. Huner and, M.C. Akuner
}

\begin{abstract}
In this study, a new multidisc and layer winding toroidal axial flux permanent magnet open slotted (MLTAFPMOS) synchronous alternators are designed and magnetic analysis was performed. Axial flux (AF) alternators are a very good candidate for wind turbine applications. However, one of the disadvantages AF alternators is to increase AF alternator diameter with $\mathrm{AF}$ alternator power. The junction points of AF alternator rotor shaft and disc have a very huge torques via occurring from inner rotor diameter forces to outer rotor diameter forces. Therefore mechanically problems emerge with increasing alternator powers. The ideal solution for this situation is to use a multidisc structure. In this study, a multidisc design for LTAFPMOS synchronous alternator was developed. A 3d solid model of the developed design was obtained. Then magnetic analyzes were performed via Maxwell. It is decided that the multidisc structure is ideal to increase the alternator power as a result of analyzes. In addition, forces at the junction points is decreased via multidisc structures.
\end{abstract}

Index Terms - Axial flux alternator, Maxwell, Permanent magnet, Toroidal winding

\section{INTRODUCTION}

$\mathrm{I}^{\mathrm{N}}$ N RECENT YEARS, a lot of study has been done to obtain electricity from wind energy, that is one of the renewable energy sources. One of them is about alternator development for wind turbines. Especially with the discovery of neodymium magnets in 1980's, with this discovery the use of permanent magnets has also begun in alternators. Especially for the last 20 years; Axial Flux Permanent Magnet(AFPM) alternators have gained importance. The axial flux machines are disk shaped and the magnetic flux path moves along the two disks. Therefore, these types of machines are called AFPM machines.

E. HUNER, is with Department of Energy Systems Engineering University of Kirklareli University, Kirklareli, Turkey, (e-mail: engin.huner@klu.edu.tr) (1

M.C. AKUNER, is with Department of Mechatronic Engineering University of Marmara, Istanbul, Turkey, (e-mail: akuner@marmara.edu.tr) (iD)

Manuscript received September 13, 2017; accepted January 08, 2018. DOI: $10.17694 /$ bajece.410190
Considering the work done on AFPM alternators; the air gap and the change in magnet angle of AFPM motor is examined. It is stated that a minimum magnetic flux change is performed for 26 degree in the work done. Besides, the most suitable air space value is analyzed as $4 \mathrm{~mm}$ [1]. In the study, a coreless AFPM rhomboidal wound alternator was designed [2]. The design was run at $400 \mathrm{~Hz}$. It is also emphasized that it is an ideal design for aircraft, ships and electric vehicles due to its low weight. In another study, a toroidal wound alternator was developed to apply the small wind turbine [3]. In this study; it is emphasized that it is the ideal alternator type for wind turbines due to its low cost, great moment and direct drive ability [3-4].

A hybrid design model for the coreless AFPM alternator is presented [5]. This hybrid structure includes both analytical calculations and programs using the Finite Element Method (FEM). For analytical calculations, a genetic algorithm based method was used of Powell's method. Powell's method is more suitable than the genetic algorithm that requires high processor power. Therefore, with this hybrid method, values such as minimum permanent magnet (PM), maximum power and optimum air gap are calculated in a shorter time.

In one study; an AFPM alternator that produces micro level power is produced [6]. The micro AFPM alternator consists of magnets embedded in the polymer rotor and two silicon printed circuit model stators. The design has a diameter of $7.5 \mathrm{~mm}$, an output power of $1.1 \mathrm{~mW}$ and a speed of $30,000 \mathrm{rpm}$ (revolution per minute). For the last 10 years, it has been emphasized that work is accelerated especially in terms of micro power generation. Many studies have used the coreless AFPM alternator structure [7-9]. This construction has advantages in terms of simple structure and low cost $[1,8,10$ 12]. In many studies about the magnetic analysis of the AFPM alternator design have obtained ANSYS's Maxwell program. In one study, multidisc constructions have been proposed to obtain maximum power at different wind speeds than wind turbines $[9,13]$. In addition, they suggested field weakening methods based on varying wind speeds in the AFPM alternators [12]. They have achieved the polarization by applying the dc winding instead of the magnet. There are also 
studies in the literature on vertical axis small scale alternator models with magnetic levitation for small wind turbines [14]. When we review the literature, we can sort out the studies made in the following articles.

- New type prototype development

- Alternators that generating power at micro levels

- Alternators with DC winding excitation

- Field weakening methods

- Cogging torque reduced methods

- Alternators with multidisc structure

\section{MATERIAL AND METHOD}

With the increase of energy demand in recent years, there has been a tendency towards renewable energy sources. One of the renewable energy sources is wind energy. One of the most important parts of turbines are alternators that designed to obtain electricity from wind energy.

For the last 20 years, especially with the discovery of the neodymium magnets, study on permanent magnet alternators has increased significantly. The most important of these studies is the axial flux permanent magnet (AFPM) alternators.

Variable wind speed has triggered studies on different methods such as field weakening, serial-parallel connection configurations, different prototype alternators. In this study, one of these methods that multidisc and layer winding toroidal axial flux permanent magnet open slotless (MLTAFPMOS) synchronous alternators.

In this study, a 3d solid model of MLTAFPMOS synchronous alternator was constituted. Then, the magnetic analysis was performed and the work was completed. In this study, MLTAFPMOS synchronous alternator is a good candidate to obtain maximum power from variable wind speeds.

\subsection{D solid modeling of the design}

The designed MLTAFPMOS synchronous alternator consists of five stators, four bi-directional rotors and two unidirectional rotors. Thus, it is possible to take five times more power than a stator-two rotor structure. In besides, depending on the wind power, MLTAFPMOS synchronous alternator step into five stages and produce maximum power at every stage. The 3D solid model of the design is given in figure 1. MLTAFPMOS synchronous alternator consisting of 5 stators is designed as open slotted and toroidal winding layer winding structure.

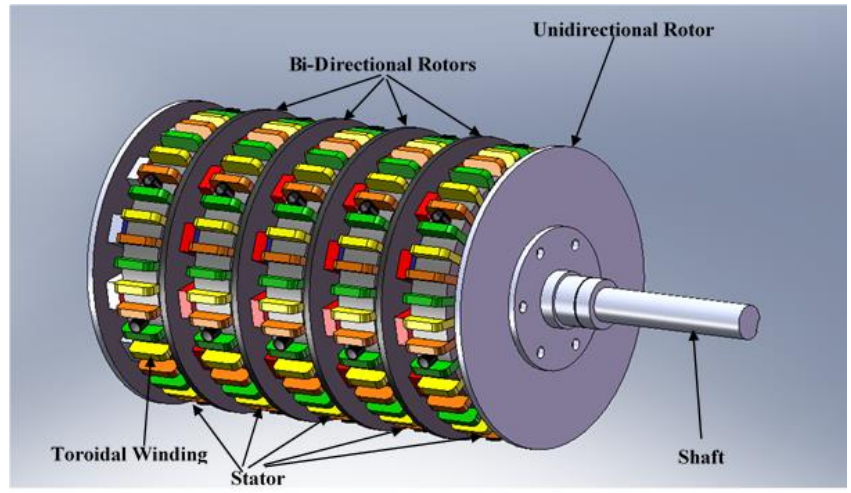

Fig.1. 3D model of MLTAFPMOS synchronous alternator
The open slotted structure used in the design reduces the production costs. However, it increases the cogging torque at high levels. The cogging torque is that are distortions in the moment due to the interaction between the magnets and the slot edges. Therefore, the cogging torque is an undesirable condition. When the literature is examined, it is seen that studies related to techniques for reducing cogging torque. The layer winding structure reduces the cogging torque while increasing the air gap. In addition to this, increasing the air gap reduces the alternator performance. In order to prevent this, a layer winding structure was applied to the increased air gap. This winding structure is given in figure 2. In Figure 2; there is two slots of the toroidal core and the toroidal winding structure is shown for a sloot of the core. Outer slot winding is shown the winding in the air gap. The height of the outer slot winding is determined by the magnetic analysis with Maxwell program. In these analyzes, the average air gap magnetic flux value should be at least 0.5 Tesla. As another criterion, the air gap should be increased till close to the minimum cogging torque.

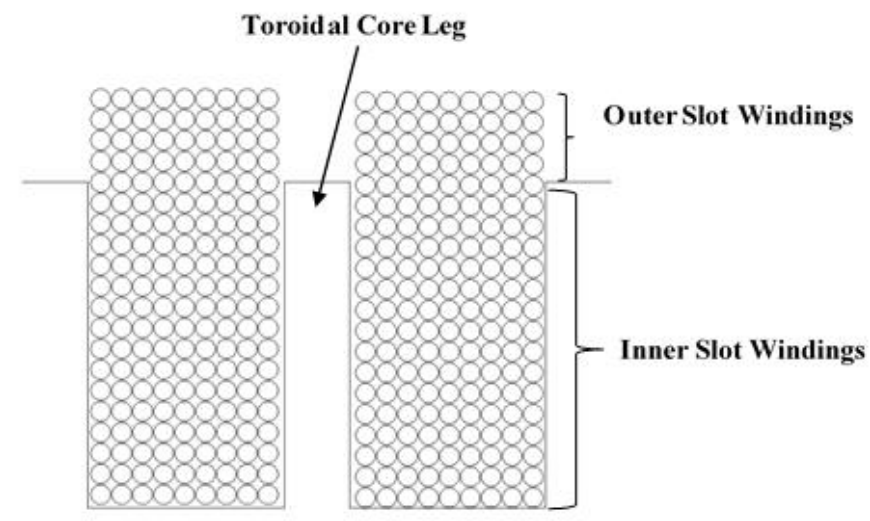

Figure 2. Slot winding structure of the MLTAFPMOS synchronous alternator

\subsection{General equation of the wind turbine}

Wind turbines starts with at a power of $1 \mathrm{~kW}$ and go up to 6 MW. The tower height and rotor diameter increment with the increase of power in the wind turbine. In particular, the increment in rotor diameter is necessary to achieve the intended power. Wind turbines are generally divided into two parts. The first is the horizontal axis turbines and the second is the vertical axis turbines.

In figure 3; wind turbines are given for horizontal and vertical axis. A basic wind turbine consists of tower, blades, anemometer, alternator, gear box (to speed up), pitch, yaw and braking systems. The wing angles are adjusted to better utilize the wind speed with the wing rotation mechanism (pitch control). Also, with tower rotation mechanism (yaw control), it is possible to catch maximum wind power by turning towards the tower wind direction in the direction of information obtained from anemometer. On the vertical axis turbines, there are no wing angles and tower rotation mechanisms. 

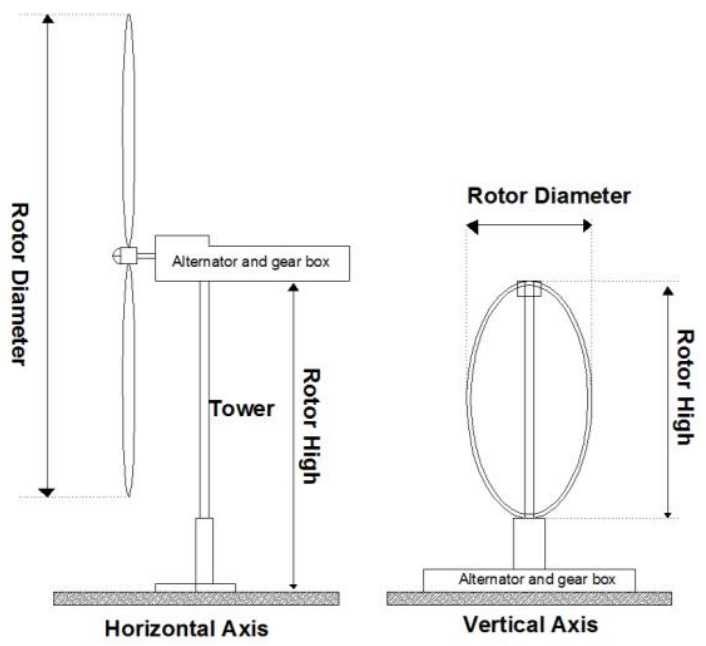

Figure 3. Horizontal and vertical axis wind turbine

The rotor diameter of the wind turbine, the density of the air, the wind speed and the rotor radius affect the power generated by the wind. The maximum power that can be achieved is given in formula (1).

$$
P_{m}=\frac{1}{2} \rho \pi R^{2} C_{p} u^{3}
$$

$P_{m}-$ is the maximum power to be achieved

$\rho$ - is the density of the air $(\mathrm{kg} / \mathrm{cm} 3)$

$\mathrm{R}$ - is the radius of the Rotor $(\mathrm{m})$

$C_{p}$-is the power factor

$\mathrm{u}-$ is the wind speed $(\mathrm{m} / \mathrm{sn})$

The power factor $C_{p}$ is obtained from formulas 2 and $3 . \beta$ indicates rotor blade angle. $\lambda$ is a coefficient related to angular velocity $\mathrm{w}$, wind velocity $\mathrm{u}$, and rotor blade diameter $\mathrm{R}$. Therefore, from the formula 1 and 2 , because of the turbine swept area increases, the larger rotor diameter, the greater mechanical power to be applied to the alternator input. However, the gear box system used in the conventional system is not available due to the direct connection to the system in the MLTAFPMOS synchronous alternator which is designed for the operation. Hence, the overall turbine efficiency is increased in this directly driven design.

$$
\begin{aligned}
\lambda_{i} & =\left[\frac{1}{(\lambda+0.08 \beta)}-\frac{0.035}{\left(\beta^{3}+1\right)}\right]^{-1} \\
C_{p}\left(\beta, \lambda_{i}\right) & =0.4654\left[\frac{116}{\lambda_{i}}-0.4 \beta-5\right] e \frac{20.24}{\lambda_{i}}
\end{aligned}
$$

\subsection{General equations of the design}

The mechanical parameters of the designed MLTAFPMOS synchronous alternator are given in Table I.
TABLE I

GEOMETRIC DIMENSIONS OF THE MLTAFPMOS SYNCHRONOUS ALTERNATOR

\begin{tabular}{lc}
\hline Name of the Parameter & Value \\
\hline Outer diameter of the stator & $210 \mathrm{~mm}$ \\
Inner diameter of the stator & $130 \mathrm{~mm}$ \\
Core height of the Stator & $40 \mathrm{~mm}$ \\
Slot number of the Stator & 42 \\
Number of the Stator & 5 \\
Pole number of the Rotor & 14 \\
Magnet sizes of the Rotor & $40 \times 20 \times 10(\mathrm{~mm})$ \\
Number of the Rotor & 6 \\
\hline
\end{tabular}

When Table I is examined, the design has six rotors and five stator. Two of the rotors are outer rotor and the other three are double sided. In the design, the input torque of the synchronous alternator of the MLTAFPMOS is calculated as in Equation 4 by dividing the input power obtained by multiplying the efficiency of formula 1 by the angular speed.

$$
T=\frac{P_{m} \eta}{w}
$$

The electromagnetic torque which should occur in the MLTAFPMOS synchronous alternator is obtained from formula 5 .

$$
T_{e}=\frac{1}{4} \alpha_{i} m_{1} I_{a} N_{1} k_{w 1} B_{m}\left(D_{o u t}^{2}-D_{i \mathrm{n}}^{2}\right)
$$

$T_{e}$ - is the electromagnetic torque ( $\left.\mathrm{Nm}\right)$

$\alpha \mathrm{i}-\mathrm{is}$ the ratio of the distance between the poles to the pole width (mm)

$m_{1}-$ is the number of phase

$I_{a}-$ is the current of the winding

$N_{1}-$ are the number of the phase turns

$K_{w 1}-$ is the coefficient of the winding

$D_{\text {out }}$ - is the Outer diameter of the stator

$D_{i n}-$ is the Inner diameter of the stator

\subsection{Magnetic analyzes}

The magnetic analysis of the MLTAFPMOS synchronous alternator was carried out with the Maxwell program of ANSYS's. The first step of the design is to create the 3D solid model to be analyzed in Maxwell. For each calculation, Maxwell divides the full model into triangular prisms and processes them based on the finite element method. So the bigger the model, the longer it takes to process. For this purpose, the points that are repeated in the program period are cut off as master and slave. Therefore, the section is taken as the slice of the model. The values obtained are multiplied by the number of cross sections taken and the actual values are reached. In the magnetic analysis of the MLTAFPMOS synchronous alternator, magnetic analysis was performed based on a stator and a rotor. Since five stator, six rotor, total 10 faces of the system is analyzed, the analysis of one face of the system is carried out, it is necessary to take 10 times the analysis results. Thus, calculations were taken 10 times faster. The full model is given in Figure 4. 


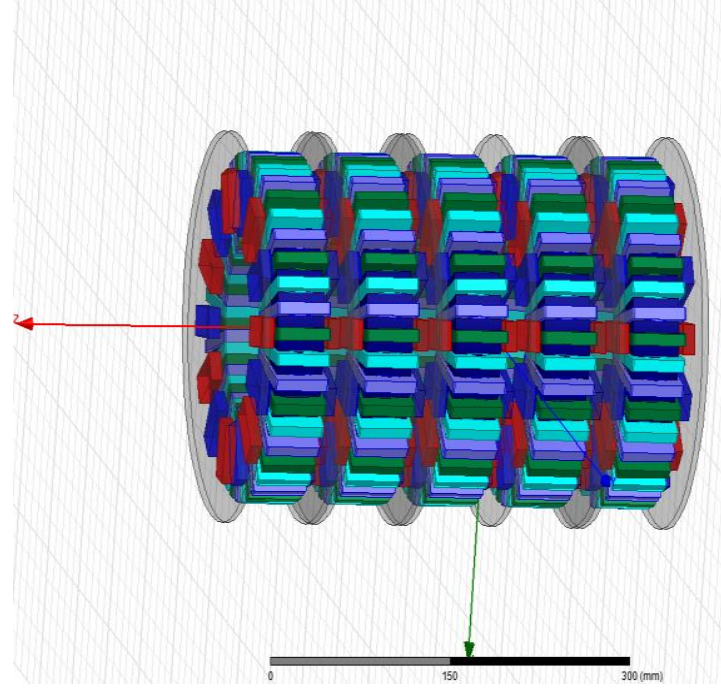

Fig.4. Full model of MLTAFPMOS synchronous alternator

In Figure 4, one out of five the full model given in Maxwell was taken and analyzes were carried out. The distribution of the magnetic flux density on the stator surface is given in Figure 5. In Figure 5, magnetic flux densities of about 1.6 tesla are observed in the core foot parts. Because of the saturating point not overcome, the received design values are suitable.

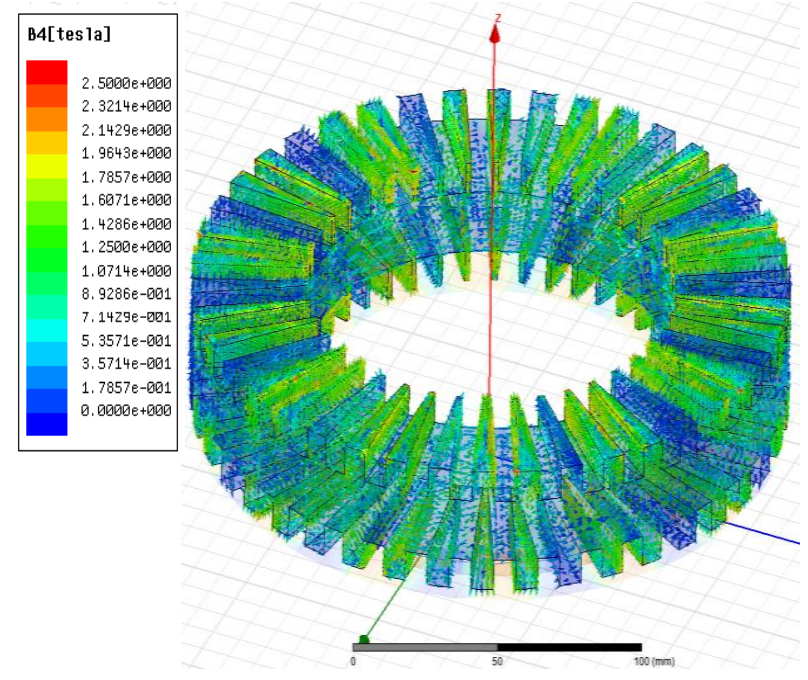

Fig.5. Magnetic flux distribution at the stator surface

Figure 6 shows the change in magnetic flux along a contour in the air gap. As shown in Figure 6, the effect of open slots is to pull down the maximum points of the curve. The magnitude of the indentations in the curves in the middle gives us an idea about the cogging torque. The greater the change, the higher the cogging torque values. In Figure 7 , the magnetic flux is varied along the contour of the air gap for slot depths between $10 \mathrm{~mm}$ and $15 \mathrm{~mm}$. It appears that the interaction is not too great along the $5 \mathrm{~mm}$ difference. The reason for this is that the distance between the core and the magnet is too large because of the layer winding structure.

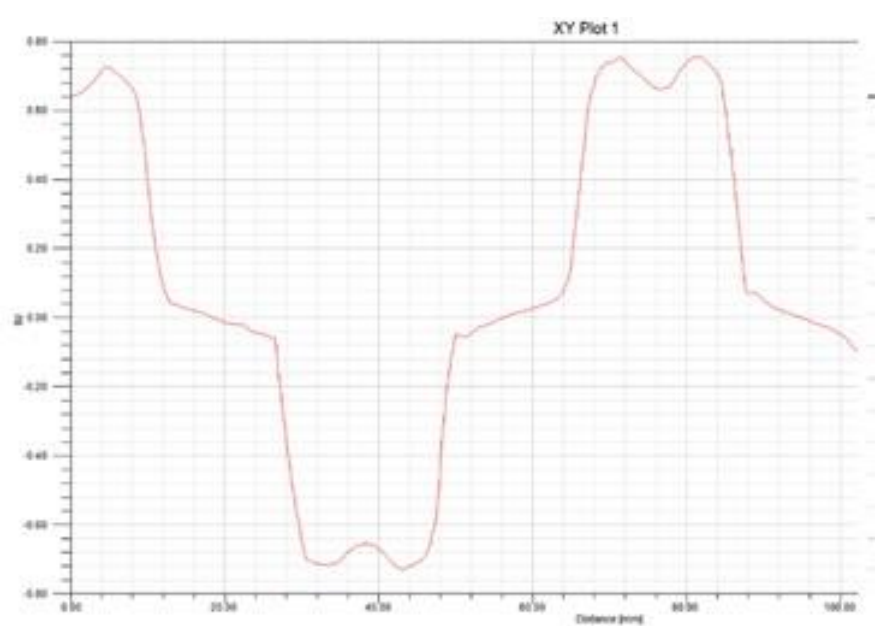

Fig.6. Magnetic flux change along a contour in the air gap

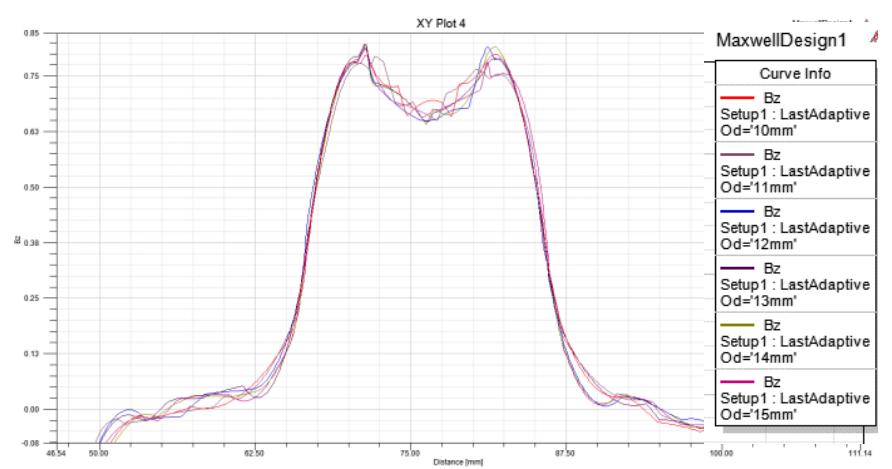

Fig.7. Magnetic flux change for slot depths values between $10 \mathrm{~mm}-15 \mathrm{~mm}$

Table II shows the values of the slot depth from $10 \mathrm{~mm}$ to 15 $\mathrm{mm}$ at $1 \mathrm{~mm}$ intervals, the average value of the magnetic flux density generated in the core volume and the average magnetic flux density in the surface taken in the air gap.

TABLE II.

AVERAGE VALUE OF MAGNETIC FLUX DENSITY DUE TO SLOT DEPTH

\begin{tabular}{ccc}
\hline $\begin{array}{c}\text { Slot depth } \\
\text { "Sd" (mm) }\end{array}$ & $\begin{array}{c}\text { B average Core } \\
\text { Volume (Tesla) }\end{array}$ & $\begin{array}{c}\text { B average In Air Gap } \\
\text { (Tesla) }\end{array}$ \\
\hline 10 & 0.756420485313839 & 0.636215991696493 \\
11 & 0.80875438869431 & 0.691729613591648 \\
12 & 0.865781444548061 & 0.771454864412778 \\
13 & 0.923232529198211 & 0.861203957792007 \\
14 & 0.976091446257511 & 0.956279998026163 \\
15 & 1.02224023011257 & 1.07317382960829 \\
\hline
\end{tabular}

When the magnetic flux densities for air space and core volume are examined, it is seen that they are close to each other. For this reason, the mean magnetic flux density values in the core volume can be taken instead of the air gap in the analyzes. It is also seen that the average air gap magnetic flux density value increases with the slot depth. Therefore, the appropriate value of the slot depth is determined by considering the mechanical properties, winding properties and cogging torque. In Figure 8, while the slot depth is $10 \mathrm{~mm}$, the generated moment value is taken. The absence of fluctation along the figure indicates that the cogging torque is low. This 
is caused by the layered winding structure. Hence, it is shown in the obtained analysis results that the alternator can operate with low cogging torque without being affected by slot depth.

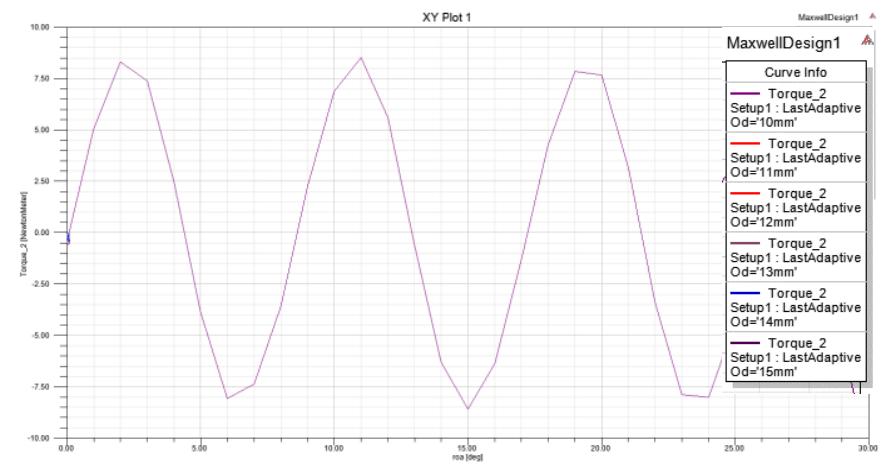

Fig.8. The moment curve of the MLTAFPMOS synchronous alternator

\section{DISCUSSION AND CONCLUSION}

In this study, magnetic analysis of MLTAFPMOS synchronous alternator that is a new design was analyzed. In AFPM open-slot alternators, the cogging torque is a major problem. The suggested new design is also supported by analyzes that reduce the cogging torque value to a minimum value. Increasing the diameter of the AFPM alternator for large power, however, increases production costs due to large axial forces on the shaft. There is also no continuous constant input moment in the wind turbines. Multidisc structure is presented to increase the power with the suggested system. With the multidisc structure, the power transmitted by the wind shaft each disk stator is entered to provide maximum efficiency in operation of the system. In the work done, instead of all the multidisc structure Maxwell's 3D magnetic analysis, by performing magnetic analyzes of one out of five, time savings have been achieved. A curve near the sinus value is also achieved in the obtained moment curve. It is also seen that the cogging torque is very low in this curve. The change in slot depth affects the in an open slotted AFPM alternator. With the multilayer winding structure given in the design, the cogging torque is reduced due to the increased air gap and the effect of decreasing power with the increase of the air gap is reduced to the minimum value thanks to the layered winding structure.

The proposed MLTAFPMOS synchronous alternator is easy to use and is suitable for use in wind turbines with minimum cogging torque. The multidisc structure also improves the efficiency and reduces the axial forces that force the shaft. After this work, research and development studies can be done for the use of AFPM alternators of different structures in wind turbines in multiple structures. Besides, with the multidisc structure of the present design, the potentials in different applications can be explored. In addition, the results of the analysis can be compared with the experimental data obtained by making a prototype study of the present design.

\section{REFERENCES}

[1]. Akuner, C. \& Huner, E. The Air Gap and Angle Optimization in the Axial Flux Permanent Magnet Motor, Electronics and Electrical Engineering, 2011, 110(4)

[2]. Caricchi, F. Crescimbini, F. Honorati, O. Performance of CorelessWinding Axial-Flux Prmanent Magnet Generator with Power Output at $400 \mathrm{~Hz}, 300 \mathrm{r} / \mathrm{m}$, IEEE Transactions on Industry Applications, Vol.34, No.2, 1999, pp.1263-69.

[3]. Muljadi Eduard, C.P. Butterfield, Yih huie Wan, Axial-flux modular permanent-magnet generator with a toroidal winding for wind-turbine applications, IEEE Transactions on Industry Applications Vol.35, No.4, 1999, pp. 831-36.

[4]. Chalmers, B. J., W. Wu, E. Spooner, An axial-flux permanent-magnet generator for a gearless wind energy system, IEEE Transactions on Energy Conversion, Vol.14, No.2, 1999, pp.251-56.

[5]. Wang Rong Jie, Maarten J. Kamper, Kobus Van Der Westhuizen, Jacek F. Gieras, Optimal design of a coreless stator axial flux permanentmagnet generator, IEEE Transactions on Magnetics Vol.41, No.11, 2005, pp. 55-64.

[6]. Holmes Andrew S., Guodong Hong,Keith R. Pullen, Axial-Flux Permanent Magnet Machines for Micropower Generation, Journal of Microelectromechanical Systems, Vol.14, No.1, 2005, pp. 54-62.

[7]. Chan, T. F., L. Lai, An axial-flux permanent-magnet synchronous generator for a direct-coupled wind-turbine system, IEEE Transactions on Energy Conversion Vol.22, No.1, 2007, pp.86-94.

[8]. Hosseini Seyed Mohsen, Mojtaba Agha-mirsalim, Mehran Mirzaei Permanent-Magnet Generator, Vol.44, No.1, 2008, pp.75-80.

[9]. Minaz Mehmet Recep, Mehmet Çelebi, Design and analysis of a new axial flux coreless $\{P M S G\}$ with three rotors and double stators, Results in Physics (7), pp.183-88.

[10]. Huner, Engin. Caner, Akuner. Axial-flux synchronous machines compared with different stator structures for use in working, Przeglad Elektrotechniczny Vol.88, No.11, 2012, pp. 174-177.

[11]. Hüner, Engin. Küçük Güçlü Rüzgar Türbinleri İ̧̧in 3D Sey Programi ile Ipms Alternatörün Elektromanyetik Tasarımı Ve Analizi, Kırklareli University Journal of Engineering and Science, Vol.2, No.1, 2016, pp.60-73.

[12]. Naeini Vahid, Mohammad Ardebili, New axial flux PM less synchronous machine with concentrated DC field on stator, International Journal of Electrical Power and Energy Systems, (67), 2015, pp. 651-58.

[13]. Kalender, Osman et al., A new axial flux permanent magnet synchronous alternator autonomously adapted to wind speeds, Measurement: Journal of the International Measurement Confederation (69), 2015, pp. 87-94.

[14]. Ghulam, Ahma. Uzma, Amin. "Design, construction and study of small scale vertical axis wind turbine based on a magnetically levitated axial flux permanent magnet generator, (101), pp. 286-92.

\section{BIOGRAPHIES}

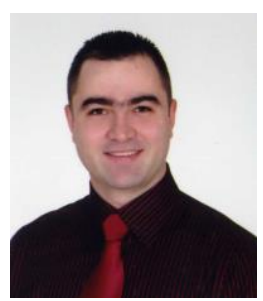

ENGIN HUNER He received Bachelor, Master and $\mathrm{PhD}$ degree in Electrical Education of Abant İzzet Baysal University, in Electronical Engineering of Gebze High Technology Institute and in Electrical Education of Marmara University. $\mathrm{He}$ has been assistant professor in the energy system engineering of Kirklareli University. He has worked mainly electrical machines and renewable energy.

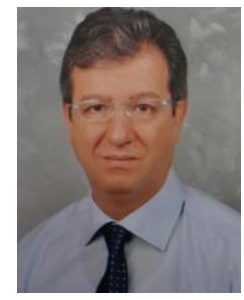

M. CANER AKUNER He received Bachelor, Master and $\mathrm{PhD}$ degree in Electrical Education of Marmara University. He has been associate professor in the mechatronics engineering of Marmara University. He has worked mainly electrical machines and electromagnetics systems. 